Bangladesh J. Plant Taxon. 27(1): 201-204, 2020 (June)

(C) 2020 Bangladesh Association of Plant Taxonomists

\title{
SEEDLING HERBARIUM: A PRIORITY
}

\author{
ANIMESH Bose* AND N.D. PARIA ${ }^{1}$ \\ Department of Botany, Vidyasagar College, 39 Sankar Ghosh Lane, \\ Kolkata-700006, West Bengal, India
}

Keywords: Herbarium; Methodology; Seedling morphology; Significance.

A herbarium is a store-house or collection of dried, pressed plant mounted on sheet bearing a detailed data label and stored in strong cupboard in systematic sequence (Stace, 1989). The pressed and dried plant sample is permanently mounted and strapped to a sheet of paper (of standard weight and type, measuring ca. $28 \mathrm{~cm} \mathrm{x} 42 \mathrm{~cm}$ ) along with a documentation label. Concept of herbarium was first given by Luca Ghini (1490? - 1556), a Professor of Botany at the University of Bologna, Italy, who mounted the pressed dried plants on paper to serve as a longterm record (Bridson and Forman, 1992). Herbarium in a single word is the library of the plant world. As of December 1 2017, there are approximately 3,001 herbaria in the world today, with approximately $387,007,790$ specimens that document the earth's vegetation for the past 400 years (Thiers, 2018). Not only angiosperms, but the other groups, such as gymnosperms, pteridophytes, bryophytes, macro fungi, and macro algae are also represented by herbarium specimens. Funk (2004) described utmost 72 different uses of a herbarium related to teaching and research of taxonomy, systematics, ecology, anatomy, morphology, conservation biology, biodiversity, ethnobotany, anthropology, and paleobiology.

Since inception, the herbarium of Angiosperms always uses the adult, reproductive stages as it helps in identification work. However, here we are proposing another stage of flowering plant for herbarium preparation, i.e. the seedling stage or juvenile stage. Seedlings usually the most transitory of life history stages, provides opportunities to explore novelties, as well as life continuum features and vulnerabilities and trade-off that, ultimately, are key to population and community dynamics. Seedling stage is arguably the busiest phase in plants lifetime (Farnsworth, 2008) and a bottleneck in the continuum of a seed plant life cycle as it not only faces unpredictable environment but also have low levels of morphological and physiological defenses. If a plant can be identified in seedling stage, then it can be protected from numerous environmental and anthropogenic hazards of its life processes. This will stop early-stage decline of our biodiversity and promote conservation of the medicinally important plants. Numerous literatures dealing with seedling morphology showed its significance in different botanical disciplines (Paria, 2014). With such profound importance, the seedling stage of all the habits of angiosperms should be considered as an item of documentation by preparation of herbarium.

The methodology for preparation and maintenance of a seedling herbarium specimen is almost similar with the usual herbarium specimen but there are some dissimilarities, which are discussed below:

1. Collection of seedling in different stages of growth, from (para)cotyledon stage to first leaf/first two leaves stage to subsequent leaves / next leaves stages (third, fourth, ..... up to that stage the plant gets it matured leaf character).

2. Drying and poisoning them as mentioned for usual herbarium specimen.

*Corresponding author, e-mail: animeshbose24@gmail.com, ${ }^{1}$ Department of Botany, School of Science, Netaji Subhash Open University, Kolkata-700091, West Bengal, India. 
3. Size of the herbarium sheet and label similar as mentioned for usual herbarium specimen.

4. On the sheet the dried and poisoned seedling plants are pasted in a sequence from (para) cotyledonary stage to first leaf / first two leaves stage to subsequent leaves / next leaves stages (Fig. 1).

5. In contrast to the usual herbarium specimen, the seedling specimen has got some different parameters in its label (Fig. 2). These parameters are Name, Family, Vernacular Name, Locality, Altitude, Seedling type, Taproot, Hypocotyl, Paracotyledon / Cotyledon, First leaf / First two leaves, Next leaves, Habitat, Collected by, Determined by, Field No., and Date.

The information on germination, tap root, hypocotyl, paracotyledon / cotyledon, epicotyl, first leaf / first two leaves, subsequent leaves of a plant are obtainable through its seedling herbarium that equivalently will help in identification of the plant. For example, the available information for seedling herbarium specimen of Clitoria ternatea $\mathrm{L}$. has been described below.

Clitoria ternatea L., Sp. Pl. 2: 753 (1753). Baker in Hook, f., Fl. Brit. Ind. 2: 208 (1876); Cooke, Fl. Bomb. Pres, (reprint ed.) 1: 105 (1958). (Up to $6^{\text {th }}$ leaf stages)

Seedling epigeal, phanerocotylar. Taproot strongly elongating, $5.0-5.5 \mathrm{~cm}$ long, soft, whitish grey, curved, glabrous; side roots profuse, with nodules. Hypocotyl strongly elongating, 4.0-4.5 $\mathrm{cm}$ long, terete, lower part light green and upper part deep green, hairy. Paracotyledons two, opposite, oblique, exstipulate, petiolate, fleshy, green; petiole $0.1-0.2 \mathrm{~cm}$, hairy, flattened; blade oblong $(1.6-1.7 \mathrm{~cm} \times 0.5-0.6 \mathrm{~cm})$; base oblique, apex rounded, margin entire; primary vein one, semicraspedodromous; surface glabrous. Intemodes terete, green, soft, densely hairy; first intemode 2.4-2.6 cm long, second one 1.7-1.8 cm long; next intemodes increasing, slender. First two leaves opposite, simple, stipulate (two, free lateral), petiolate, herbaceous; petiole $1.2-1.5 \mathrm{~cm}$, terete, pubescent; blade ovate $(2.4-2.6 \mathrm{~cm} \times 1.2-1.4 \mathrm{~cm})$, base obtuse, apex acute, margin entire; primary vein one, semicraspedodromous; surface glabrous. Subsequent leaves alternate, compound, unipinnate, imparipinnate, trifoliolate upto sixth to eighth leaves stages, next leaves with 5-7 leaflets, stipulate, stipellate, petiole base pulvinate, petiolule pulvinate, leaflet blade ovate-elliptic, terminal leaflet larger in size. Other characters almost same as that of first of two leaves. (Fig. 1).

Specimens examined: Salt Lake Sector V, Kolkata (W. B.), Sanyal and Paria 1502, dated 11.06.2007; Salt Lake Sector III, Kolkata (W. B.), Sanyal and Paria 1546, dated 21.06.2007; Barasat, North 24 Parganas (W. B.), Sanyal and Paria 1624, dated 06.07.2007.

Different stages are required as this provide more stable and reliable characters, and also reveal the different stages of maturity of the concerned plant. The heteroblastic development of angiosperm leaves is also revealed through the different seedling stages. The seedling herbarium of Clitoria ternatea (Fig. 1) is showing heteroblasty in the development of leaves. Here the first two leaves are opposite, simple, ovate whereas the next leaves are alternate, compound, trifoliolate. The heteroblasty is a well-known morphological parameter in plant developmental biology, but why and how this variation occur in leaves is a significant topic of investigation in present days. This development is an advantage of a seedling herbarium over a usual herbarium. While dealing with a group of taxa, the available seedling characters can be used to prepare a key, which promote easy identification of plants at seedling stage. Not only identification but by protecting the seedlings we can save our biodiversity also, that is the most significant word in research community in $21^{\text {st }}$ century. 


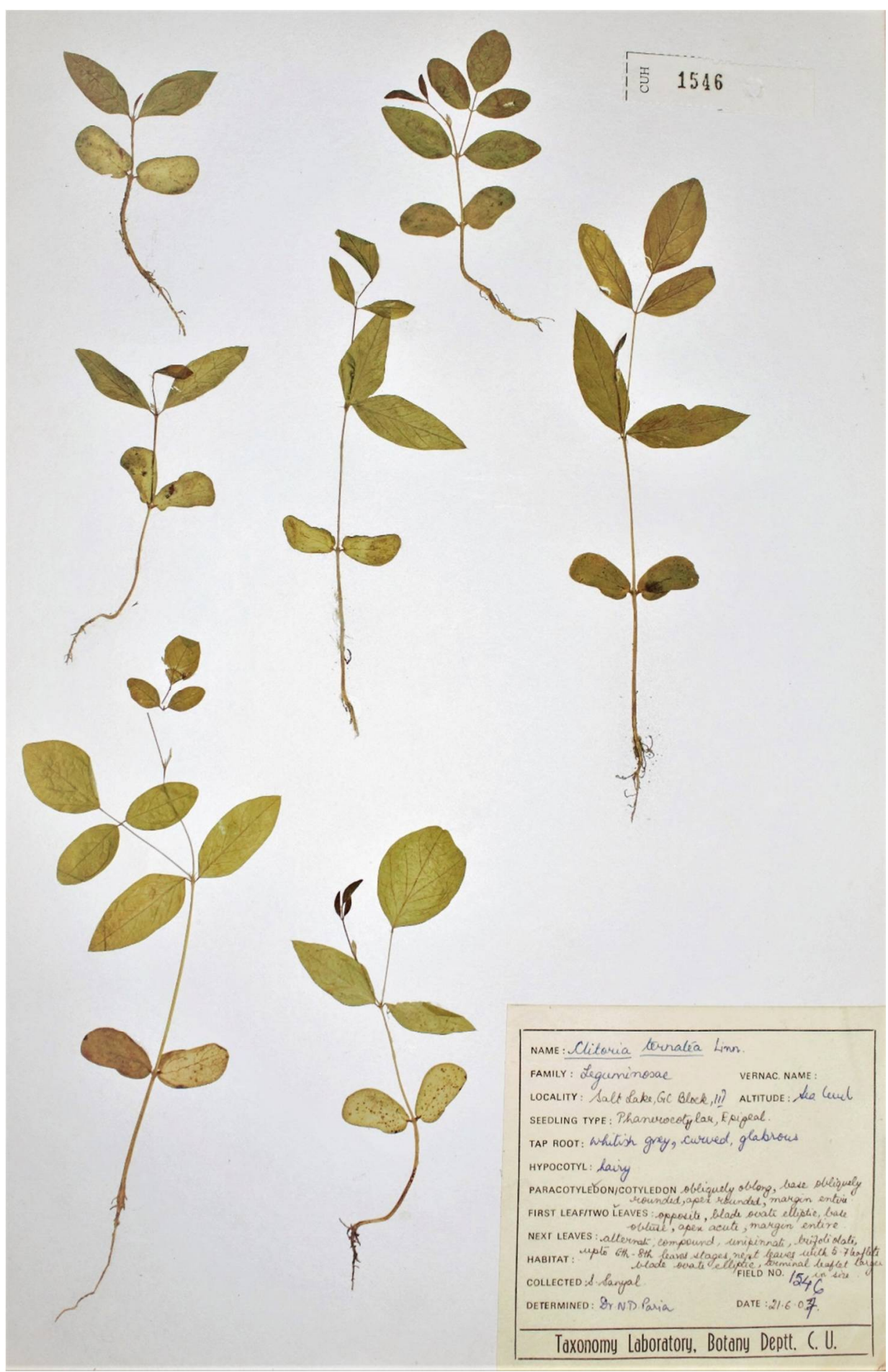

Fig. 1. A seedling herbarium of Clitoria ternatea L. up to sixth leaf stages. 
As such, a seedling herbarium has got uses like traditional herbarium. So, these should be treated as priority matter beside a usual herbarium in every national and international herbaria as well as in plant research centers.

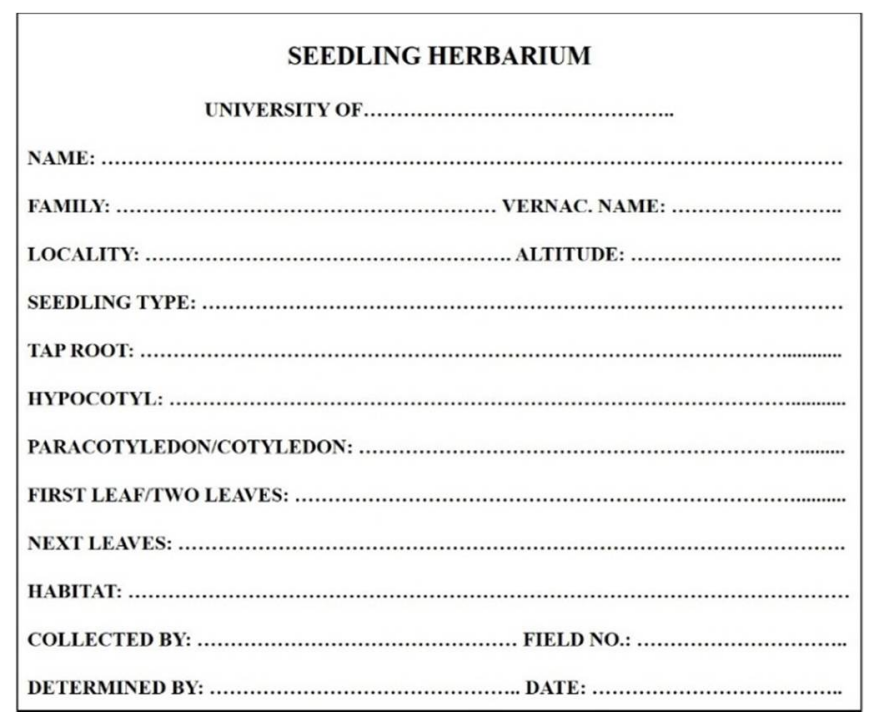

Fig. 2. Sample of a seedling herbarium label.

\section{Acknowledgements}

The author is grateful to the Head, Department of Botany, University of Calcutta for providing infrastructural facilities. Thanks are due to Late Dr. Sanghamitra Sanyal, Assistant Professor, Bethune College to use the seedlings of Clitoria ternatea L.; for editorial comments and valuable ideas from the anonymous reviewer's help in modifying the manuscript.

\section{References}

Bridson, D. and Forman, L. 1992. The Herbarium Handbook, Revised edition. Royal Botanic Gardens, Kew, Great Britain, pp. 4.

Farnsworth, E.J. 2008. Physiological and morphological changes during early seedling growth: roles of phytohormones. In: Leck, M.A., Parker, V.T. and Simpson, R.L. (Eds.), Seedling Ecology and Evolution. Cambridge University Press, Cambridge, UK, pp. 150-171.

Funk, V. 2004. 100 Uses for a Herbarium (Well at Least 72). Division of Botany, The Yale University Herbarium, Peabody Museum of Natural History, Yale University, pp. 1-4.

Paria, N.D. 2014. Botanical research in India in the domain of seedling morphology in relation to taxonomy. Science and Culture 80(9-10): 262-270.

Stace, C.A. 1989. Plant Taxonomy and Biosystematics, Second Edition. Edward Arnold, London, pp. 197.

Thiers, B. 2018. Index Herbariorum: A global directory of public herbaria and associated staff. New York Botanical Garden's Virtual Herbarium. http://sweetgum.nybg.org/science/ih/. 